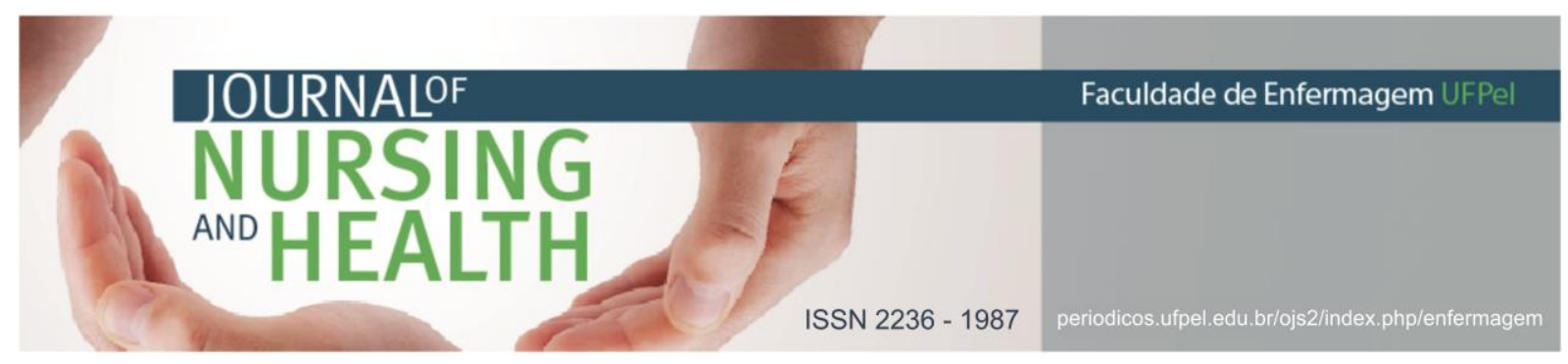

EDITORIAL

\title{
A contação de histórias como tecnologia na promoção da autonomia e participação da criança hospitalizada no cuidado de enfermagem
}

\author{
Storytelling as technology in promoting autonomy and participation of hospitalized \\ children in nursing care
}

\section{La narración de cuentos como tecnología para promover la autonomía y participación de niños hospitalizados en cuidados de enfermería}

Brondani, Jeanine Porto ${ }^{1}$; Wegner, Wiliam²

Como citar este editorial: Brondani JP, Wegner W. A contação de histórias como tecnologia na promoção da autonomia e participação da criança hospitalizada no cuidado de enfermagem. J. nurs. health. 2019;9(3):e199311

Contar histórias para crianças é uma ação que há muitos anos se realiza em diferentes cenários: domicílios, escolas e serviços de saúde. São momentos de interação e imaginação capazes de acessar sentimentos e desejos que atravessam o mundo adulto e infantil. Dentre tantas narrativas infantis, há algumas que se diferenciam por abordar o processo saúde-doença e os cuidados de enfermagem como eixo central, cuja criança é protagonista da história e do cuidado. A contação de histórias pode ser considerada uma tecnologia, pois a sua utilização na assistência à criança hospitalizada é definida a partir de um objetivo a ser alcançado, necessitando de preparo, planejamento e, também, avaliação. ${ }^{1}$

O hospital é um ambiente que restringe a criança em muitos aspectos, como alimentação, higiene, sono, brincadeiras, entre outros. Além disso, a criança acometida por alteração no processo saúde-adoecimento é exposta a procedimentos invasivos o que a torna ainda mais vulnerável e ambivalente a este contexto, o que pode predispor inclusive a eventos adversos.

Cuidar das crianças nessa condição requer competências que são específicas e que instrumentalizam o profissional para se relacionar com elas. Entretanto, em diversos momentos, os procedimentos, exames, medicações e orientações são conversadas apenas com os responsáveis/acompanhantes/familiares, fazendo a criança ficar "a parte" do que está acontecendo com pouca participação no processo decisório. Essa perspectiva é resultado de um modelo de biológico e fragmentado, pautado em tecnologias duras e leve-duras, que desconsidera a dimensão cuidadora. ${ }^{2}$

1 Enfermeira. Doutora em Enfermagem. Universidade Federal do Maranhão (UFMA), Maranhão, Brasil. E-mail: jeaninebrondani@yahoo.com.br http://orcid.org/0000-0002-3061-4199

2 Enfermeiro. Doutor em Enfermagem. Universidade Federal do Rio Grande do Sul (UFRGS), Rio Grande do Sul, Brasil. E-mail: wegnerwiliam@gmail.com http://orcid.org/0000-0002-0538-9655 


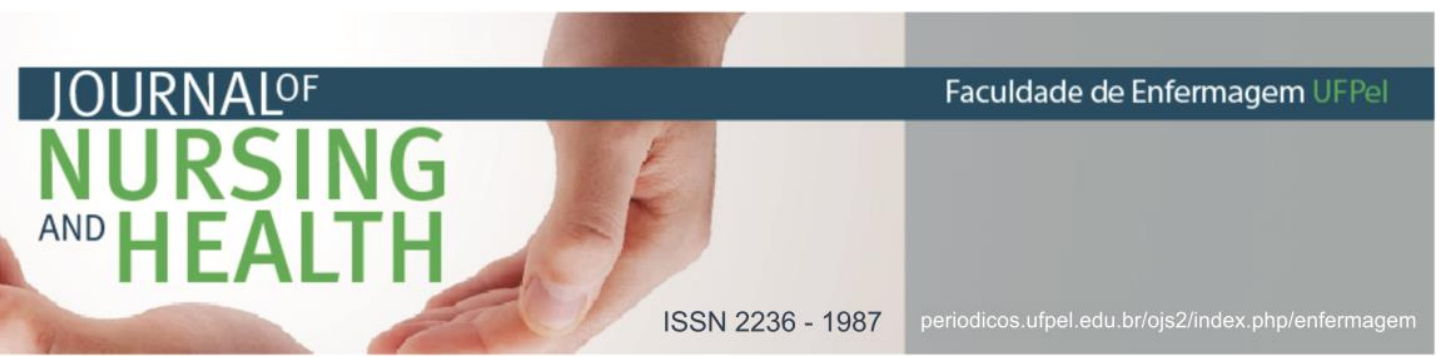

Como consequência, pode gerar experiências negativas, traumas, resistências e dificultar o processo de trabalho dos profissionais de saúde.

A compreensão da criança pode variar com a idade e a etapa do desenvolvimento cognitivo, porém a subjetividade deve ser valorizada em qualquer momento da vida. Não é suficiente distraí-las ou apenas explicar, mas oportunizar momentos efetivos de interação quando as crianças podem ter atendido seu melhor interesse. Mesmo que elas não possam legalmente consentir de maneira independente, a possibilidade de assentimento das crianças sempre deve ser considerada. ${ }^{3}$

Para o sucesso nas intervenções de enfermagem e promoção de prática seguras, há diferentes tecnologias disponíveis para a qualidade da assistência que possibilitam a inclusão da criança no cuidado de forma respeitosa, colaborativa e científica, como o brinquedo terapêutico, as histórias infantis, as escalas padronizadas, entre outras. Por isso, o Conselho Federal de Enfermagem, determina que a técnica do brincar/brinquedo terapêutico seja utilizada na assistência à criança e a família, bem como, contemplada no processo de enfermagem e registrada em prontuário. ${ }^{4}$

Utilizar histórias específicas para intervir nas necessidades das crianças é uma estratégia importante na construção de um espaço de interação entre o profissional e ela, de modo a produzir cuidado em conjunto, individualizado e seguro. A criança, no tempo dela, pode interagir e imaginar a partir do que está vendo, ouvindo e/ou lendo. Há um estímulo à identificação com o personagem e o reconhecimento do enfermeiro como agente de cuidado. Nesse encontro, a criança pode falar por si, se expressar, questionar e, também, aprender. Além disso, é possível colocar elementos que são importantes para ela e escolher como pode ser colaborativa no cuidado, o que respeita os direitos previstos em lei e configura-se como tecnologia leve em saúde. Por esse motivo, pressupõe um modo de fazer que reúne saberes específicos, tais como a fase do desenvolvimento da criança, a situação clínica e como a história será utilizada a fim de fazer a relação com o que a criança está vivendo. ${ }^{1-5}$

A contação de histórias como tecnologia de cuidado na hospitalização infantil amplia as ações de enfermagem para além de procedimentos técnicos, pois é capaz de transformar positivamente o encontro terapêutico, colaborar na participação e na autonomia da criança no cuidado de enfermagem e promover a segurança do paciente. Além disso, pela linguagem simples e acessível, pode ser utilizada nas dimensões brincar, educar e cuidar de acordo com o objetivo que os profissionais definirem. Esta estratégia é capaz de colaborar no empoderamento dos profissionais na medida em que conseguem perceber a criança de forma mais integral, construindo vínculo e estimulando-as para o desenvolvimento. ${ }^{1}$

Recomenda-se esforços de pesquisadores em propor estudos para compreender melhor as diferenças/proximidades da contação de histórias e o brinquedo terapêutico, bem como na autonomia e participação da criança em diferentes circunstâncias de cuidado. 


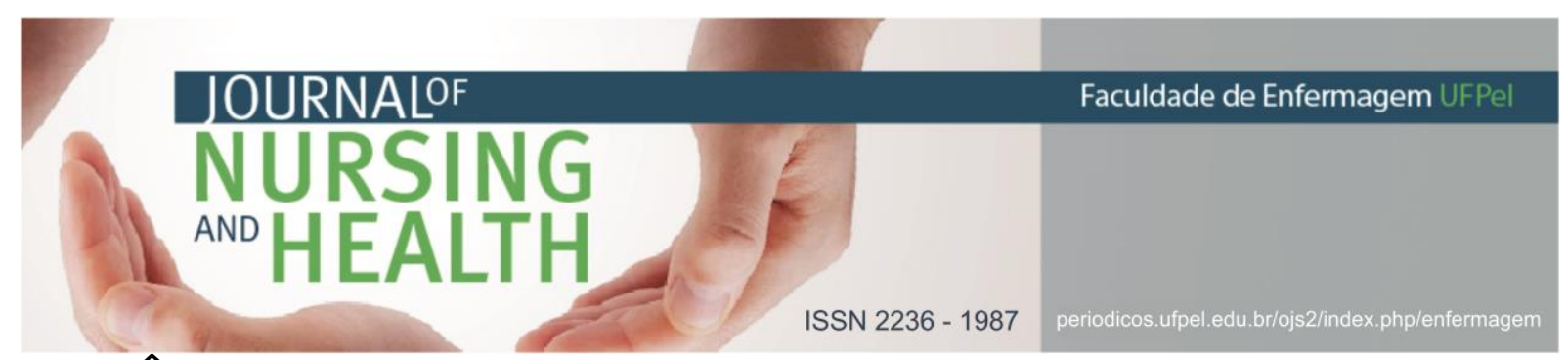

\section{REFERÊNCIAS}

1 Brondani JP. A contação de histórias como tecnologia de cuidado à criança hospitalizada sob a ótica de enfermeiros [tese] [Internet]. Porto Alegre (RS). Universidade Federal do Rio Grande do Sul; 2018[acesso em 2019 dez 05]. Disponível em: https://www.lume.ufrgs.br/handle/10183/196110

2 Merhy EE. A perda da dimensão cuidadora na produção da saúde. In: Campos CR, Malta DC, Reis AF. Sistema Único de Saúde em Belo Horizonte: reescrevendo o público. Rio de Janeiro: Xamã; 1998. p. 1-13.

3 Carnevale F. Considerações éticas em enfermagem pediátrica. Rev. Soc. Bras. Enferm. Pediatras (Online). [Internet]. jul 2012[acesso em 2019 dez 05]; 12(1):37-47. Disponível em: https://sobep.org.br/revista/images/stories/pdf-revista/vol12n1/v.12_n.1-art4.pesq-consideracoes-eticas-enfermagem.pdf

4 Conselho Federal de Enfermagem (COFEN). Resolução $n^{\circ} 546$, de 09 de maio de 2017. Dispõe sobre a utilização da técnica do brinquedo/brinquedo terapêutico na assistência à criança e família hospitalizadas [Internet]. 2017[acesso em 2019 nov 13]. Disponível em: http://www.cofen.gov.br/resolucao-cofen-no05462017_52036.html

5 Brasil. Lei $n^{\circ} 8.969$, de 13 de julho de 1990. Dispõe sobre o Estatuto da Criança e do Adolescente (ECA) e dá outras providências [Internet]. Brasília; 1990[acesso em 2019 nov 15]. Disponível em: http://www.planalto.gov.br/ccivil_03/LEIS/L8069.htm

Data de publicação: 12/12/2019 